\title{
Polymorphism of the inosine triphosphate pyrophosphatase gene predicts ribavirin-induced anemia in chronic hepatitis $\mathrm{C}$ patients
}

\author{
TAKASHI NISHIMURA ${ }^{1}$, RIE OSAKI $^{1}$, MAKOTO SHIOYA $^{1}$, HIROTSUGU IMAEDA ${ }^{1}$, TOMOKI AOMATSU ${ }^{1}$, \\ TAKAYUKI TAKEUCHI ${ }^{2}$, YOSHIAKI OKUMURA ${ }^{3}$, YOSHIHIDE FUJIYAMA ${ }^{1}$ and AKIRA ANDOH ${ }^{4}$ \\ ${ }^{1}$ Department of Medicine, Shiga University of Medical Science, Otsu; ${ }^{2}$ Department of Medicine, Notogawa Hospital, \\ Higashioumi; ${ }^{3}$ Department of Medicine, Social Insurance Shiga Hospital, Otsu; ${ }^{4}$ Division of Mucosal Immunology, \\ Graduate School of Medicine, Shiga University of Medical Science, Otsu, Shiga, Japan
}

Received August 15, 2011; Accepted October 25, 2011

DOI: $10.3892 / \mathrm{mmr} .2011 .659$

\begin{abstract}
Ribavirin (RBV)-induced anemia is a serious side effect of pegylated interferon (PEG-IFN) plus RBV therapy which is the standard care most effective for hepatitis $C$ virus (HCV) infection. In the present study, we investigated the association of inosine triphosphate pyrophosphatase (ITPA) genotypes with $\mathrm{RBV}$-induced hemoglobin $(\mathrm{Hb})$ reduction in HCV patients treated with PEG-IFN/RBV therapy. The genotypes of the ITPA rs1127354 single nucleotide polymorphism were determined in 179 patients with HCV infection. Among them, 52 patients were treated with PEG-IFN/RBV. The frequency of the ITPA major allele (CC) was $76.3 \%$ and that of the minor allele (CA and AA) was $23.7 \%$. A rapid decrease in $\mathrm{Hb}$ levels during the initial 4 weeks was observed in patients with the ITPA major allele (CC), but not in patients with the ITPA minor allele (C/A and AA). Hb levels at 4 weeks were significantly lower in patients with the ITPA major allele than the levels in patients with the minor allele. Out of the 41 patients, 6 (14.6\%) with ITPA major allele had $\mathrm{Hb}$ levels $<10 \mathrm{~g} / \mathrm{dl}$ and 11 patients $(26.8 \%)$ had a decline in $\mathrm{Hb}$ of $>3 \mathrm{~g} / \mathrm{dl}$. None of the patients with the ITPA minor allele had such data. There were no significant differences in virological responses of HCV-RNA between patients with the ITPA major allele and those with the minor allele. In conclusion, the ITPA genotypes may be a useful marker for prediction of RBV-induced anemia.
\end{abstract}

\section{Introduction}

Hepatitis $\mathrm{C}$ virus (HCV) is the leading cause of chronic liver disease. It accounts for $70 \%$ of all chronic hepatitis cases, $40 \%$ of all cases of liver cirrhosis and $60 \%$ of hepatocellular carci-

Correspondence to: Dr Akira Andoh, Division of Mucosal Immunology, Shiga University of Medical Science, Seta Tsukinowa, Otsu, Shiga 520-2192, Japan

E-mail: andoh@belle.shiga-med.ac.jp

Key words: hepatitis C virus, ribavirin, hemolytic anemia nomas (HCC) $(1,2)$. Since the successful eradication of HCV is associated with a reduced risk of liver cirrhosis and $\operatorname{HCC}(3,4)$, antiviral therapy plays a crucial role in the management of $\mathrm{HCV}$-infected patients. Currently, pegylated interferon (PEGIFN) plus ribavirin (RBV) is considered to be the standard of care most effective for chronic hepatitis $\mathrm{C}$ (5-7), but the rate of sustained virological response (SVR; HCV RNA negative for 24 weeks after the cessation of therapy) is approximately $50 \%$ in patients with $\mathrm{HCV}$ genotype 1, the most common genotype found in populations in many countries $(5,6)$. Furthermore, $20-30 \%$ of HCV genotype 1 patients are non-responders to PEG-IFN/RBV therapy (3).

PEG-IFN therapy sometimes causes bone marrow suppression $(8,9)$, and dose reduction may be required in such cases. However, dose reduction is associated with a potentially compromised treatment outcome. Rates of viral clearance are significantly reduced in patients who cannot be maintained on at least $80 \%$ of their PEG-IFN/RBV dosage for the duration of treatment (10). Prediction of risk for such complications would be clinically useful for selecting patients for therapy, as well as planning the monitoring frequency. Since bone marrow suppression remains prevalent in patients with early-stage fibrosis, a genetic biomarker for predicting risk of treatment for bone marrow suppression would be particularly useful at the start of therapy.

RBV-induced anemia is a serious side effect of therapy which leads to dose reduction of $\mathrm{RBV}$, but the mechanism underlying RBV-induced anemia remains to be determined. De Franceschi et al previously reported that membrane oxidative damage as well as impairment of erythrocyte $\mathrm{Na} / \mathrm{K}$ pump activity are responsible for RBV-induced hemolytic anemia (11). Studies show that single nucleotide polymorphisms (SNPs) in the inosine triphosphate pyrophosphatase (ITPA) locus are associated with anemia in patients treated with combination therapy (12-14). Two SNPs that are associated with ITPA enzyme activity were identified in the Caucasian population (12), but the Japanese population lacks one of these SNPs $(14,15)$. A limited number of reports have demonstrated the association of ITPA genotypes with RBV-induced anemia, but further studies concerning the role of ITPA genotypes on RBV-induced anemia are required. Furthermore, the effect of the SNPs on the therapy outcome should be investigated. 
In the present study, we investigated the association of ITPA genotypes with hemoglobin reduction and therapeutic outcome in HCV patients treated with PEG-IFN/RBV therapy.

\section{Patients and methods}

Study populations. A total of 176 patients with chronic HCV infection (HCV serotype 1, $\mathrm{n}=126$ and serotype 2, $\mathrm{n}=50$ ), who were treated at the Hospital of the Shiga University of Medical Science, the Notogawa Hospital and the Social Insurance Shiga Hospital were included in the study. Among them, 52 HCV1 patients were treated with PEG-IFN/RBV therapy. Table I lists the demographic features of the patients receiving PEG-IFN/RBV therapy. The patients received weekly injections of PEG-IFN $\alpha 2 \mathrm{~b}$ at $1.5 \mu \mathrm{g} / \mathrm{kg}$ body weight or PEG-IFN $\alpha 2 \mathrm{a}$ at 180 or $90 \mu \mathrm{g}$, and the oral administration of RBV for 24-72 weeks. The amount of RBV was adjusted based on the subject's body weight (600 mg for $<60 \mathrm{~kg}, 800 \mathrm{mg}$ for $60-80 \mathrm{~kg}, 1,000 \mathrm{mg}$ for $>80 \mathrm{~kg}$ ). Only patients with $>75 \%$ compliance with the prescribed doses of PEG-IFN/RBV were included in this study. Informed consent was obtained from all patients. The ethics committee of each participating medical center approved this study.

Serotyping. Serotyping was performed using an enzyme immunoassay-based Murex assay (Murex Diagnostics Inc., Norcross, GA, USA).

Genotyping. The samples were genotyped for ITPase C94A (rs1127354) using the TaqMan ${ }^{\circledR}$ SNP Assays (Applied Biosystems Inc., Foster City, CA, USA) as previously described (16). Homozygosity (AA) or heterozygosity (CA) of the minor sequence was defined as having the ITPA minor allele, whereas homozygosity for the major sequence (CC) was defined as having the ITPA major allele. The HCV RNA levels were analyzed using the TaqMan RT-PCR test. The measurement ranges of these assays were 1.2-7.8 $\log \mathrm{IU} / \mathrm{ml}$.

Statistical analysis. Hardy-Weinberg equilibrium (HWE) analysis was performed in these subjects by comparing the detected distribution of allele frequencies to the theoretical distribution estimated from the SNP allelic frequencies. $\mathrm{P}>0.05$ (Chi-square test) was considered to indicate equilibrium. The categorical variables were presented as frequencies and percentages when required. The continuous variables were reported as the means $\pm \mathrm{SD}$ (range). Multivariate logistic regression analysis with stepwise forward selection was performed with a criterion of $\mathrm{P}<0.05$ for the inclusion or removal of variables. All statistical analysis used the Ekuserutoukei 2008 (Social Survey Research Information Co., Ltd., Tokyo, Japan) software. A P-value $<0.05$ was considered to denote statistical significance.

\section{Results}

The genotype frequencies of the ITPA polymorphisms in patients with HCV $(n=176)$ are shown in Table II. The frequency of the ITPA major allele, defined as homozygosity for the major sequence (CC), in HCV serotype 1 patients (76.2\%) was similar to that of serotype $2(76.5 \%)$. In total, the
Table I. Patient baseline characteristics.

\begin{tabular}{lc} 
No. & 52 \\
Gender (male/female) & $32 / 20$ \\
Age $($ years $)$ & $62.0 \pm 10.5(38-76)$ \\
Weight $(\mathrm{kg})$ & $62.0 \pm 11.1(40-90.7)$ \\
Body mass index $\left(\mathrm{kg} / \mathrm{m}^{2}\right)$ & $22.3 \pm 2.8(17.0-30.1)$ \\
Baseline hemoglobin level $(\mathrm{g} / \mathrm{dl})$ & $13.7 \pm 1.4(10.8-17.9)$ \\
Baseline platelet level $\left(10^{6} / \mu \mathrm{l}\right)$ & $15.5 \pm 5.2(3.9-29.9)$ \\
Initial ribavirin dose $(\mathrm{mg} / \mathrm{day}), \mathrm{n}(\%)$ & \\
200 & $1(1.9 \%)$ \\
400 & $4(7.7 \%)$ \\
600 & $23(44.2 \%)$ \\
800 & $22(42.3 \%)$ \\
1,000 & $2(3.8 \%)$ \\
Hemoglobin level at week $4(\mathrm{~g} / \mathrm{dl})$ & $12.1 \pm 1.4(8.3-14.1)$ \\
Hemoglobin decline at week $4(\mathrm{~g} / \mathrm{dl})$ & $2.2 \pm 1.3(0.7-5.2)$ \\
\hline
\end{tabular}

Data unless otherwise specified are presented as the means \pm SD (range).

Table II. Genotype distribution of ITPA SNP rs1127354.

\begin{tabular}{lccccc}
\hline & \multicolumn{5}{c}{ rs1127354 } \\
\cline { 2 - 6 } & $\mathrm{CC}$ & $\mathrm{CA}$ & $\mathrm{AA}$ & $\mathrm{C}$ & $\mathrm{A}$ \\
& $(\%)$ & $(\%)$ & $(\%)$ & $(\%)$ & $(\%)$ \\
\hline HCV serotype 1 (n) & 96 & 27 & 3 & - & - \\
& $(76.2)$ & $(21.4)$ & $(2.4)$ & $(86.9)$ & $(13.1)$ \\
HCV serotype 2 (n) & 38 & 10 & 2 & - & - \\
& $(76.5)$ & $(19.6)$ & $(3.9)$ & $(86.3)$ & $(13.7)$ \\
Total (n) & 134 & 37 & 5 & - & - \\
& $(76.3)$ & $(20.9)$ & $(2.8)$ & $(86.7)$ & $(13.3)$ \\
\hline
\end{tabular}

frequency of the rs 1127354 major allele (CC) was $76.3 \%$ and the frequency of the minor allele (CA and AA) was $23.7 \%$. These data are compatible with a recent report of the Japanese population (5).

A total of 52 patients with HCV1 infection were treated with PEG-IFN/RBV therapy. These patients were stratified according to their ITPA allele type, and the decrease in hemoglobin $(\mathrm{Hb})$ levels was analyzed. As shown in Fig. 1, a rapid decrease in $\mathrm{Hb}$ levels during the initial 4 weeks was observed in patients with the ITPA major allele (CC), but such a phenomenon was not observed in patients with the ITPA minor allele (C/A and AA). Hb levels at 4 weeks were significantly lower in patients with the ITPA major allele than levels in patients with the minor allele. The rate of clinically significant anemia, defined as either a decline in $\mathrm{Hb}$ levels of $>3 \mathrm{~g} / \mathrm{dl}$ or $\mathrm{Hb}<10 \mathrm{~g} /$ $\mathrm{dl}$, was analyzed. This criteria is the threshold at which RBV dose reduction is recommended. As shown in Fig. 2, none of the patients with the ITPA minor allele had $\mathrm{Hb}$ levels $<10 \mathrm{~g} / \mathrm{dl}$ and a decline in $\mathrm{Hb}$ of $>3 \mathrm{~g} / \mathrm{dl}$ at 4 weeks. On the other hand, 


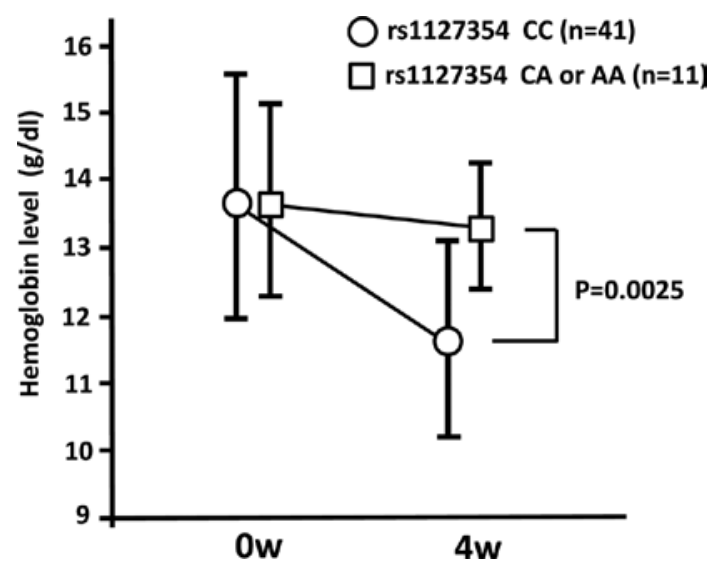

Figure 1. Association between ITPA genotypes and changes in Hb levels. A total of 52 patients with HCV1 infection were treated with PEG-IFN/RBV therapy. These patients were stratified according to their ITPA genotypes, and decrease in $\mathrm{Hb}$ levels was analyzed at 4 weeks after the start of therapy. Data are expressed as the means $\pm \mathrm{SD}$.
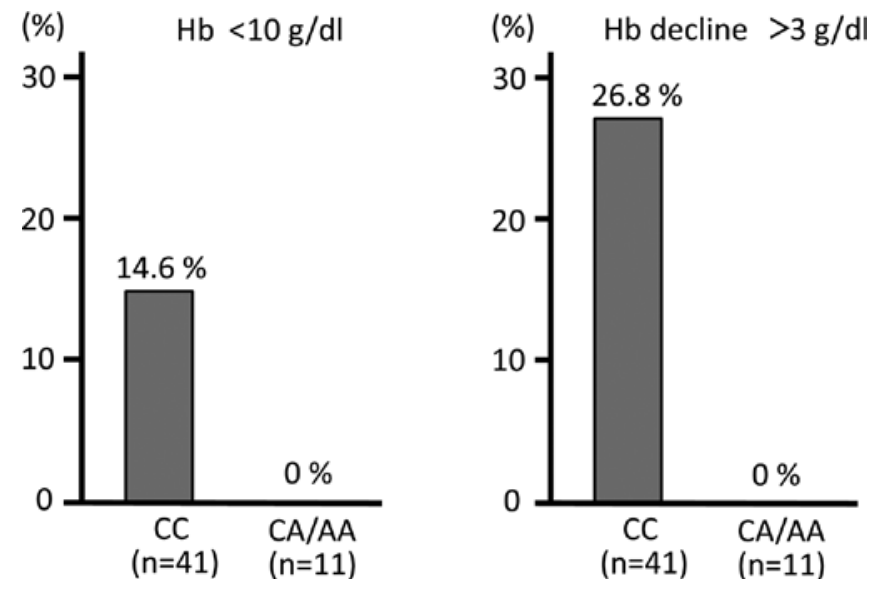

Figure 2. Association between ITPA genotypes and the rate of clinically significant anemia at 4 weeks (a decline of $>3 \mathrm{~g} / \mathrm{dl}$ or $<10 \mathrm{~g} / \mathrm{dl}$ in Hb levels).

$14.6 \%$ (6 of 41) of patients with the ITPA major allele had $\mathrm{Hb}$ levels $<10 \mathrm{~g} / \mathrm{dl}$ and $26.8 \%$ (11 of 41 ) had a decline in $\mathrm{Hb}$ of $>3 \mathrm{~g} / \mathrm{dl}$.

The association of the ITPA genotypes with virological responses was analyzed by the Kaplan-Meier method. As shown in Fig. 3, there were no significant differences in the negative rate of HCV-RNA between patients with the ITPA major allele and those with ITPA minor allele.

\section{Discussion}

PEG-IFN/RBV is the standard of care therapy for chronic $\mathrm{HCV}$ infection (5-7), but this therapy is associated with a range of treatment-limiting adverse effects. One of the most serious adverse effects is RBV-induced hemolytic anemia $(12,14)$, which affects most patients and is severe enough to require dose modification in approximately $15 \%$ of patients. Recently, a genome-wide association study of determinants of treatmentrelated anemia in individuals with chronic $\mathrm{HCV}$ genotype 1 infection identified that genetic variants leading to ITPA deficiency protect against hemolytic anemia in HCV-infected patients receiving RBV (12). In the Caucasian population,

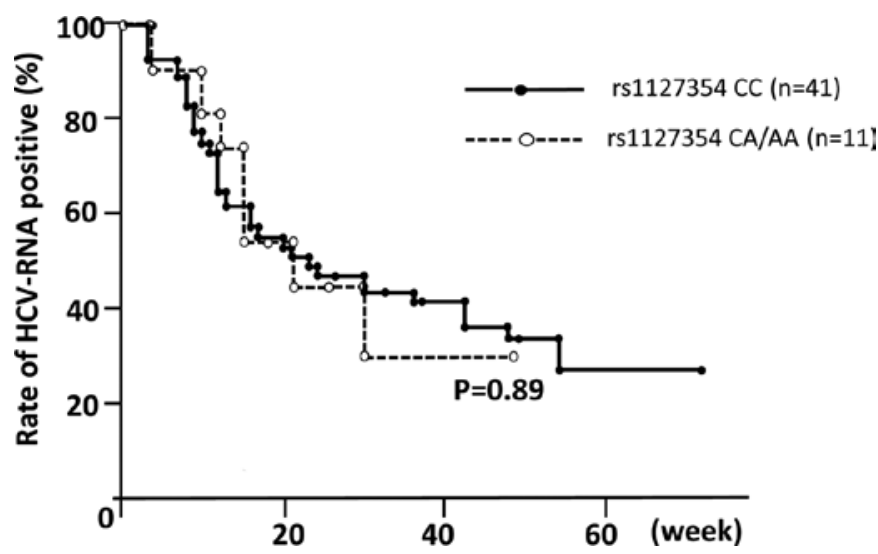

Figure 3. Comparison of the effects of ITPA genotypes on HCV positivity. Data were analyzed using the Kaplan-Meier method. There were no significant differences between the effects of the ITPA genotypes.

there are two SNPs (rs7270101 and rs1127354) that are associated with ITPA enzyme activity $(12,13)$, but one of these SNPs (rs7270101) is absent in Japanese patients (14). In this study, we confirmed the absence of rs7270101; the frequency of the rs1127354 major allele (CC) was $76.3 \%$ and that of the minor allele (CA and AA) was $23.7 \%$. These results are compatible with recent reports on the Japanese population $(5,14)$.

We investigated an association between ITPA genotypes and incidence of RBV-induced anemia. As reported by recent studies $(5,12-14), \mathrm{Hb}$ decrease is faster and more severe during the first 4 weeks of treatment in patients with the ITPA major allele (CC). The rapid decrease of $\mathrm{Hb}$ observed in major allele CC patients was associated with early reduction of RBV dosage, resulting in a lower total RBV administration. $\mathrm{Hb}$ decrease was slightly milder in this study as compared to the results of Thompson et al (13), and this may be due to the early reduction of the RBV dose in Japanese patients resulting from lower pre-treatment $\mathrm{Hb}$ levels. Initial $\mathrm{Hb}$ levels indeed had a strong influence on reduction of the RBV dose. Since reduction of $\mathrm{RBV}$ to $<80 \%$ results in a decreased rate of SVR (10), patients with pre-treatment $\mathrm{Hb}$ levels below $13.5 \mathrm{~g} / \mathrm{dl}$ or between 13.5 and $15 \mathrm{~g} / \mathrm{dl}$ who have the ITPA major allele should receive treatment with drugs such as erythropoietin to prevent reduction of RBV. Thus, we confirmed the clinical relevance of this genetic discovery. Patients who have the ITPA major allele (CC type) have a greater likelihood of rapid progress of RBV-induced hemolytic anemia and should be monitored extensively. By contrast, patients with the minor allele (CA or AA type) are unlikely to present a rapid decrease in $\mathrm{Hb}$ levels. However, since the gradual and continuous decrease of $\mathrm{Hb}$ has been reported in ITPA minor allele patients (5), a reduction in RBV dosage, but not as drastically as in patients with the major allele, should be considered.

We did not observe any significant association between the ITPA genotypes and early or late anti-HCV treatment outcomes. Similar observations have been reported by several authors $(5,12,14)$. This may reflect decreased treatment efficacy due to dose reduction of RBV in patients showing severe anemia.

The mechanism of RBV-induced hemolytic anemia remains to be elucidated (17), but a role of RBV accumulation in red blood cells is suspected. Accumulation of RBV induces membrane oxidative damage as well as impairment of 
erythrocyte $\mathrm{Na} / \mathrm{K}$ pump activity and leads to hemolysis (11). It has been reported that ITPA deficiency leads to an accumulation of inosine triphosphate in red blood cells (18). Fellay et al (12) hypothesized that ITPA competes with RBV and thereby protects cells from the lytic effects of RBV. An alternative explanation is that ITPA activity and/or ITPA levels directly or indirectly influence RBV pharmacokinetics.

In conclusion, the present study may provide a rationale for developing a therapeutic approach for targeting ITPA genotypes in PEG-IFN/RBV therapy of chronic hepatitis $\mathrm{C}$ patients. The ITPA genotypes would be a useful marker for prediction of RBV-induced anemia. Moreover, genetic testing of ITPA genotypes may be applied to establish personalized dosages in PEG-IFN/RBV therapy.

\section{Acknowledgements}

This study was partly supported by the MSD Co., Ltd., Tokyo, Japan.

\section{References}

1. Alavian SM, Tabatabaei SV, Keshvari M, et al: Peginterferon alpha-2a and ribavirin treatment of patients with haemophilia and hepatitis $C$ virus infection: a single-centre study of 367 cases. Liver Int 30: 1173-1180, 2010.

2. Welzel TM, Morgan TR, Bonkovsky HL, et al: Variants in interferon-alpha pathway genes and response to pegylated interferon-alpha2a plus ribavirin for treatment of chronic hepatitis $C$ virus infection in the hepatitis $\mathrm{C}$ antiviral long-term treatment against cirrhosis trial. Hepatology 49: 1847-1858, 2009.

3. Kurosaki M, Tanaka Y, Nishida N, et al: Pre-treatment prediction of response to pegylated-interferon plus ribavirin for chronic hepatitis C using genetic polymorphism in IL28B and viral factors. J Hepatol 54: 439-448, 2011.

4. Yasui K, Harano Y, Mitsuyoshi H, et al: Steatosis and hepatic expression of genes regulating lipid metabolism in Japanese patients infected with hepatitis C virus. J Gastroenterol 45: 95-104, 2010.

5. Azakami T, Hayes CN, Sezaki H, et al: Common genetic polymorphism of ITPA gene affects ribavirin-induced anemia and effect of peg-interferon plus ribavirin therapy. J Med Virol 83: $1048-1057,2011$
6. Hadziyannis SJ and Koskinas JS: Differences in epidemiology, liver disease and treatment response among HCV genotypes. Hepatol Res 29: 129-135, 2004.

7. Hadziyannis SJ, Sette H Jr, Morgan TR, et al: Peginterferonalpha2a and ribavirin combination therapy in chronic hepatitis $\mathrm{C}$ : a randomized study of treatment duration and ribavirin dose. Ann Intern Med 140: 346-355, 2004.

8. Fried MW, Shiffman ML, Reddy KR, et al: Peginterferon alfa-2a plus ribavirin for chronic hepatitis $C$ virus infection. N Engl J Med 347: 975-982, 2002.

9. Manns MP, McHutchison JG, Gordon SC, et al: Peginterferon alfa-2b plus ribavirin compared with interferon alfa-2b plus ribavirin for initial treatment of chronic hepatitis $\mathrm{C}$ : a randomised trial. Lancet 358: 958-965, 2001.

10. McHutchison JG, Manns M, Patel K, et al: Adherence to combination therapy enhances sustained response in genotype-1-infected patients with chronic hepatitis C. Gastroenterology 123: 1061-1069, 2002

11. De Franceschi L, Fattovich G, Turrini F, et al: Hemolytic anemia induced by ribavirin therapy in patients with chronic hepatitis $\mathrm{C}$ virus infection: role of membrane oxidative damage. Hepatology 31: 997-1004, 2000.

12. Fellay J, Thompson AJ, Ge D, et al: ITPA gene variants protect against anaemia in patients treated for chronic hepatitis $\mathrm{C}$. Nature 464: 405-408, 2010.

13. Thompson AJ, Santoro R, Piazzolla V, et al: Inosine triphosphatase genetic variants are protective against anemia during antiviral therapy for $\mathrm{HCV} 2 / 3$ but do not decrease dose reductions of RBV or increase SVR. Hepatology 53: 389-395, 2011.

14. Ochi H, Maekawa T, Abe H, et al: ITPA polymorphism affects ribavirin-induced anemia and outcomes of therapy - a genomewide study of Japanese HCV virus patients. Gastroenterology 139: 1190-1197, 2010.

15. Ban $\mathrm{H}$, Andoh A, Imaeda $\mathrm{H}$, et al: The multidrug-resistance protein 4 polymorphism is a new factor accounting for thiopurine sensitivity in Japanese patients with inflammatory bowel disease. J Gastroenterol 45: 1014-1021, 2010.

16. Livak KJ: Allelic discrimination using fluorogenic probes and the 5' nuclease assay. Genet Anal 14: 143-149, 1999.

17. Russmann S, Grattagliano I, Portincasa P, Palmieri VO and Palasciano G: Ribavirin-induced anemia: mechanisms, risk factors and related targets for future research. Curr Med Chem 13: 3351-3357, 2006.

18. Fraser JH, Meyers H, Henderson JF, Brox LW and McCoy EE: Individual variation in inosine triphosphate accumulation in human erythrocytes. Clin Biochem 8: 353-364, 1975. 